\title{
The Librarian and the Student
}

G. Donald Smith is librarian of Mary Washington College Library, Fredericksburg, Virginia.

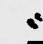

7 He FUNDAMENTAL function of the 1 library is to forward, rather than to originate, the educational program of the campus. It must provide the materials recommended, must remove so far as is possible all barriers between them and the students, and must facilitate the flow of suggestion from class lecture, conference, and syllabus to book contacts and book use. It is not only the connecting link between teaching and learning, but, where students are intelligent and inquisitive, the library can supplement from its rich resources what the classroom has failed to supply."1

All too often the professional librarian fails to appreciate fully the fact that the college library is designed primarily to be of service to the college student. Too frequently the administrator of the college library adopts without question the objectives and techniques of his predecessors. The service which we render still consists of the cataloging, the classification, the circulation of books, and the answering of reference questions on an information bureau basis. This is true in spite of the changed and changing conditions and new objectives of higher education in America.

It is unnecessary to do more than men-

1 Branscomb, Harvie, Teaching with Books: a Studv of College Libraries. Association of American Colleges and A.L.A., 1940, p. 82.

MARCH, 1941 tion here these changing circumstances. We are conscious of the tremendous increase in the number of students enrolling in the colleges. We are constantly made aware of the demand for more and more democracy in education. We have witnessed many careful criticisms and revisions of the college program of work. Under the stimulation of faculty demands we have selected and bought more books and made them more easily available to the student through open stacks and other devices. In general we have more money to spend than we had twenty years ago. We have larger and better equipped buildings and better qualified staff members. Our libraries are, for the most part, efficiently organized, smooth-running collections of books, from which individual volumes may be selected and used by the student, subject only to certain rules and regulations having to do with the length of loans, overdue fines, and the like.

The distinction should be made here that we are talking about the college library-not the library of the university, the graduate school, the research institute, and other organizations. The college in this paper is understood to be the two- or four-year undergraduate institution.

Importance of Books in the Teaching Program

With this distinction in mind we may ask, What are the factors in current college education which affect the library? The first is the greater importance of books 
and related materials in the teaching program. It does not follow from this that the emphasis is on the extensive use of books, although this is sometimes the case. It is an indication, however, that educators recognize the value of the careful and independent study of books, in contrast to a book, which are suited to the individual student and to the course of study. Thus, reserve reading lists tend to grow in size -to the consternation of the reserve desk assistants-but exact page assignments tend to diminish. The student is supposed to select for himself, with the guidance of competent instructors, the titles best suited to his need.

A second factor is the wide tendency on the part of faculty members to assign "research papers." Such assignments usually are carried on throughout the quarter or semester session and are supposed to introduce the student to methods of independent study and research on a topic of interest to him. It is research only in the most elementary sense, of course, and does not require the extensive collection of library research materials which the graduate school must possess.

Related to the second factor is the third, the establishment of some form of "honors" or "reading" courses in the college. The individual student working under this system makes extensive use of the library and follows subjects rather than definitely outlined courses of study.

The trend which these factors illustrate is toward a greater and greater use of books and library collections. It seems almost unnecessary to point out that this trend is not in itself an objective of higher education, but is merely an expression of an objective. The aim is not the extensive use of books, but the intelligent, understanding use of books.

\section{Library as an Instructional Unit}

Although there are several noble exceptions to the "conventional" college library organization, the criticism remains that contemporary library administration is not suited to the contemporary college. The fault, I believe, lies in our failure to examine closely the objectives of the college library and their relationships to the aims of the college. Such expressions as "training for democracy," "development of personality," "training for the home," "training in the profitable use of leisure time" and the like, while phrasing the hopes of higher education, are somewhat vague terms to which to hitch the practical solutions of the many administrative problems of the library. But suppose we think of our library as an instructional unit of the college rather than as an administrative unit, and take as our primary objectives the training of the individual in the arts of selecting his reading and understanding what he reads-in other words, training in the use of book collections and the art of reading.

We must grant, of course, that we can no more than supplement in the library the efforts of the major instructional unit of the college, the faculty. From our stand on such objectives as stated above, the practical problems of integrating our library service with the rest of the college activities can be more easily seen and understood. With such objectives, following the example of progressive education, we turn our attention from the materials concerned to the individual and his needs.

In the quotation with which this paper opened, the statement is made that the library "must facilitate the flow of suggestion from class lecture, conference and syllabus to book contacts and book use." 
This statement is the center of our "new" library program. The provision of various kinds of materials and making them available are problems which we must solve in carrying out the program.

\section{Close Cooperation with the Instructors}

How may we go about the attainment of these objectives? This is, of course, the important question. The suggestion already has been made that we must turn our attention from the books to the individual, from the subjects of study to the methods of study. It may follow that we shall give less attention to the detailed technical processes of book preparation and it is to be remembered that all processes are justified only in so far as they further the attainment of our aims.

The primary demand upon us will be for close cooperation with the instructor and a careful coordination of our efforts. The instructor is, after all, the person responsible for the content and method of his courses. The librarian must always be supplementary to the classroom and the librarian should have a definite understanding of what the instructor is trying to do and the methods he employs. In a sense, the librarian becomes an assistant to the teacher in the conduct of his courses. This works both ways for the teacher can help the librarian to a better understanding of what is being done, a better understanding of the individual student, and a more effective use of the library's resources.

What shall be the content of this cooperation with the faculty? First, we must stop thinking of ourselves as educational experts with answers to all problems connected with the library. The faculty member may. have some fine suggestions for us concerning the importance of this or that process or procedure.
Again, since we are attempting to integrate our service with the teaching program, may we not expect the faculty member to assist us in the exact definition of the services which we will offer and the methods we shall use? Suppose, for example, that we attempt to offer an advisory service in connection with curricular reading, a service designed to assist the student in the choice of reading materials suited to his needs, his abilities, and interests. Certainly the instructor in history can tell us a great deal about what is needed in such a service for the improvement of history study, about the history books concerned and how they may best be used, about the students involved and what they are expected to get from the books.

The coordination of our program with the teaching schedule calls for a detailed, day-by-day knowledge of what is taking place in the courses. This information we may secure from the professor and by more or less frequent visits to the classes themselves. Thus, we shall know assignments before they come up for consideration in the library and can time our own activities to the course demands.

\section{Reading Records}

We, in turn, can provide the teacher and others interested with a careful record of what the student does in the library and how he reacts to different assignments. Answers to such questions as "Which students read?" "What do they read?" "What are the relationships between reading and scholarship?" "Which subjects are receiving attention, and which are neglected?" and the like, are important, and if we give some time to the compilation and analysis of reading records, the figures we present will receive the attention they deserve. 
A second major demand upon us will be for cooperation with the student. After all, he is the individual we are trying to serve. Here as in no other phase of our work we must consider ourselves as teachers. Our meeting with the student is the moment at which all our efforts have been aimed-our book buying, our cooperation with the faculty, our administration and organization. It is the point at which we bring about that union of the class and the library, the student and the written records of his subject. It is the point at which learning takes place. The importance of this student contact cannot be exaggerated. It is the final test of our library program, for our ultimate success depends upon how effectively we do our work of teaching the use of books and libraries. We have an excellent opportunity. We meet the student informally. We give no grades, no examinations, and are not, therefore, hampered in our work by any feeling of fear on the part of the student. Our activity is purely service, not requirement.

Dr. Adler, in his How to Read a Book, ${ }^{2}$ gives as one of the important rules of reading the "coming to terms with the author." That is, we must be sure that we understand the author-his words, phrases, sentences, etc. Likewise, in our library service we must come to terms with the student-understand his needs, his interests, his abilities. In no other way can we give the student who comes to us for help the service he should expect and receive.

\section{Library's Teaching Function}

We may, if you wish, constitute ourselves a group of unofficial, informal "the-

\footnotetext{
2 Adler, Mortimer J. How to Read a Book. Simon and Schuster [c1940].
}

sis advisors" at the undergraduate level of instruction and function in somewhat the same way that the research advisor functions in the graduate school, giving individual assistance and advice where needed. We may undertake to guide and instruct the student in his attempts to read with understanding the materials assigned. We may assist him in the organization and interpretation of materials for his papers, remembering that we are not writing the papers but giving instruction in the methods of reading and study. We may further undertake to explore for and develop individual interests and hobbies of whatever subject content, turning them into positive educational activities in direct relation with the established curriculum.

Such assistance as outlined briefly above, if given with the approval and help of the faculty members, will be of unquestioned value in the attainment of the educational objectives of the college.

Since this is not an article on college library administration, I shall make no attempt to describe all the changes which the adoption of this program will bring about in the individual libraries. It goes without saying, of course, that the customary activities of book selection and acquisition, preparation, circulation, reference, and the rest will be continued-but they will be continued in a form modified by the new emphasis on the teaching function of the library.

Two features of our library administration call for immediate attention. Both are prerequisite to the establishment of this type of library service. The first is the librarian's relation to the college administrator. Such a library program calls for more than mere presidential approval. It must have the active support, both moral and financial, of the administration. 
We must, therefore, turn our first efforts toward demonstrating to the administrative officers the possibilities and methods of the program and convincing them of its desirability. Once that is done the necessary support will be forthcoming.

\section{Library Staff}

The college administration is the source of the second important feature of the program-the library staff. This is the most important single factor of the entire plan. It will succeed or fail depending upon the staff selected for the duties outlined. In my opinion, the individuals selected for this "teaching" in the library need not all be trained in library science. The primary qualification which we must require is a first-class academic training similar to that which we expect of the faculty member, without, perhaps, the subject specialization. Such training will enable the library staff members to understand the purposes, processes, and methods of the service which they are to render more easily and completely. The number of staff members required for this service depends upon local conditions-the size of the library book collection, the number of students enrolled, the library building, and the effectiveness with which our efforts at library-faculty cooperation are carried out.

Equally important is the factor of staff organization. The head librarian is naturally responsible for the service. $\mathrm{He}$ must see to it that his staff works with the highest degree of internal cooperation, that provision is made for frequent, rapid exchange of ideas, information, and experiences, that every member of the staff is constantly aware of the objectives of the service and of the activities taking place around him. Individuals and groups of the faculty, members of the library committee, and representatives of the administration should be active participants in the frequent and regular meetings of the library staff. This "teaching service" in the library can be developed and maintained only by accepting from every possible source the advice and help available, exercising carefully planned control over the conduct of the service, and keeping detailed records of the activities.

Any college library that will restate its objectives along educational lines as suggested herein, that will develop and execute a careful plan of educational service, will rapidly attain a position of prominence in the eyes of the administrative officers of the college, the faculty, its own staff members, and of the library profession at large. This has been true in every case where the library has undertaken some such program as described. With the adoption of this type of service, we integrate our library activities with the instructional program of the college, and the librarian, including in that term all members of the staff, comes into direct teaching relationship with the student. 